\title{
PENGEMBANGAN VOICE BASED IDENTIFICATION SEBAGAI PENGAMAN ROOM DOOR LOCK SYSTEM
}

\author{
${ }^{a}$ Dhimas Bayu Mehendra, ${ }^{b}$ Koko Joni, ${ }^{\text {'Kunto Aji Wibisono }}$ \\ ${ }^{\text {a,b,c }}$ Program Studi Teknik Elektro,Fakultas Teknik, Universitas Trunojoyo Madura \\ Jl. Raya Telang, PO Box 2 Kamal, Bangkalan - Madura \\ E-mail: dhimas5hendra@gmail.com,kokojoni@gmail.com,kunto.utm@gmail.com
}

\begin{abstract}
Abstrak
Pintu adalah sebuah bukaan pada dinding / bidang yang memudahkan sirkulasi antar ruangruang yang dilingkupi oleh dinding / bidang tersebut.Pintu biasanya ditemukan pada bangunan, misalnya rumah.Sebagai penghubung utama untuk keluar dan masuk ke dalam rumah, pintu menjadi salah satu bagian vital pengaman rumah.Maka perlu pengamanan khusus untuk pintu agar tidak sembarangan dapat dibuka dan dimasuki.

Dengan menggunakan suara yang memiliki perbedaan antaran suara seseorang dengan orang lain dapat dibuat sebuah sistem pengaman modul kunci. Dalam sistem ini perbedaan frekuensi suara dideteksiksi menggunakan microphone yang prosesnya dilakukan menggunakan software RAD Studio XE 7 kemudian suara yang masuk dikonversi menjadi sinyal dan dijadikan sebagai parameter yang disimpan kedalam database yang kemudian diberikan rule-rule untuk hak akses bagi pemilik suara tertentu yang dapat mengakses pintu yang dikunci dengan selenoid lock, sedangkan microcontroller hanya sebagai media yang mengirimkan sinyal elektrik ke selenoid untuk dikonversi menjadi energi mekanik yang dapat membuka pintu yang telah diimplementasikan sistem kunci otomatis.
\end{abstract}

Kata Kunci- Pengenalan Suara, FFT, System Security, solenoid.

Abstract

The door is an opening in the wall / field that facilitates the circulation between spaces surrounded by walls / fields. Doors are usually found in buildings, such as houses. As the main liaison to get out and enter the house, the door becomes a vital part of the house's safety. Then it needs special security for the door so that it can not be opened and entered.

By using voice that has a difference between someone's voice and someone else, a key module security system can be created. In this system the sound frequency difference is detected using a microphone which the process is done using RAD Studio XE 7 software then the incoming sound is converted into a signal and used as a parameter that is stored in the database which is then given rules for access rights for certain voice owners who can access the door which is locked with selenoid lock, while the microcontroller is only as a medium that sends electrical signals to the selenoid to be converted into mechanical energy which can open the door that has been implemented an automatic lock system.

Keywords - Voice recognition, FFT, Security System, solenoid.

\section{PENDAHULUAN}

Pintu adalah sebuah bukaan pada dinding atau bidang yang memudahkan sirkulasi antara ruang yang dibatasi oleh dinding.Pada pintu mempunyai jenis pengaman yang berbeda tergantung dari kebutuhan dan fungsi, contohnya adalah kunci dan pembuka berupa anak kunci.Pada dasarnya kunci dibedakan menjadi dua yaitu kunci mekanik dan kunci
elektronik.Kunci mekanik mulai ditinggalkan oleh penggunanya.Hal ini disebabkan karena dari segi keamanan yang kurang terjamin dan banyaknya pembuat kunci duplikat.Kunci elektronik dirancang untuk mengatasi kelemahan dari kunci mekanik. Harga kunci elektronik memang relatif lebih mahal dibanding kunci mekanik contohnya adalah sistem password, fingerprint, face detection, dan pembacaan smart card. 
Perilaku tidak terpuji dan tidak diingikan seringkali terjadi pada suatu ruangan yang memiliki beberapa barang berharga di dalamnya.Dan salah satu jalan untuk membawa barang yang telah dicuri adalah pintu.Sedangkan melihat berbagai macam perkembangan teknologi pada masa ini, seperti teknologi komputer, robot dll.Maka dirasa perlu untuk melakukan pengamanan terhadap pintu dengan memanfaatkan teknologi masa kini.

Pengenalan suara adalah teknik baru yang saat ini banyak dikembangkan untuk mendukung interakasi antara manusia dan komputer yang saat ini menjadi salah satu hal yang sangat potensial bagi para peneliti untuk mendalami bidang keilmuan ini, pengenalan suara ini merupakan inovasi teknologi yang dapat mengubah suara masukan menjadi teks.Pengenalan suara adalah suatu pengembangan teknik dan sistem yang memungkinkan perangkat komputer untuk menerima masukan berupa kata atau kalimat yang diucapkan oleh pengguna.

Dalam hal ini dirancang sebuah sistem keamanan pintu menggunakan pengenalan suara untuk ruangan dengan barang-barang yang berharga, agar tidak terjadi tindakan yang tidak diinginkan.Sistem yang dirancang ini memanfatkan microcontroler, komputer, software Delphi RAD Studio XE7, microphone, dan selenoid lock sebagai perangkat utama untuk membangunnya.

\section{Pengenalan Suara}

Suara manusia diciptakan oleh manusia dengan menggunakan pita suara ketika berbicara, menangis, berteriak, dll.Suara manusia secara khusus merupakan bagian dari produksi suara manusia di mana pita suara adalah sumber suara utama.Sedangkan pengenalan suara merupakan suatu usaha untun mengidentifikasi suara tersebut untuk kemudian dapat dimanfaatkan pada berbagai aplikasi.tahap pengenalan suara secara umum dibagi menjadi dua bagian, yakni tahap pembelajaran pola dan tahap pengenalan suara melalui perbandingan pola. Blok diagram pembelajaran pola dan pengenalan suara ditunjukan pada Gambar 1[1].

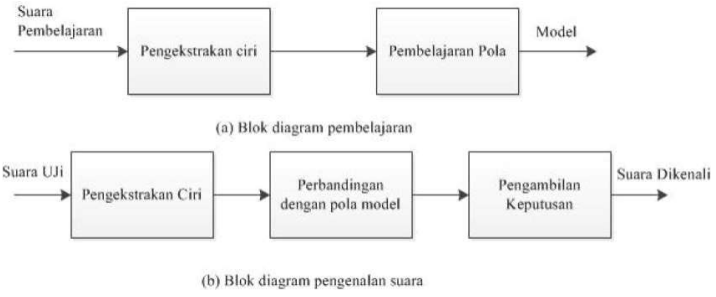

Gambar 1.Blok diagram pembelajaran pola dan pengenalan

Hampir semua teknik untuk sintesis dan pengenalan ucapan didasarkan pada model produksi ucapan manusia.Sebagian besar suara ucapan manusia dapat diklasifikasikan sebagai suara atau frikativ.Suara bersuara saat terjadi udara yang dipaksakan keluar dari paru-paru, melalui pita suara, dan keluar dari mulut dan / atau hidung. Pita suara adalah dua lapisan tipis jaringan yang membentang di udara, tepat di belakang apel adam. Sebagai respons terhadap berbagai torsi otot, kabel vokal bergetar pada frekuensi antara 50 dan $1000 \mathrm{~Hz}$, vokal adalah contoh suara bersuara. Suara yang disuarakan diwakili oleh generator pulsa motor, dengan nada (i.c., frekuensi dasar bentuk gelombang) menjadi parameter yang dapat disesuaikan[2].

Jenis - Jenis Pengenalan Suara

Berdasarkan kemampuan dalam mengenal kata yang diucapkan, terdapat 5 jenis pengenalan kata, yaitu :

1. Kata-kata yang terisolasi

Proses pengidentifikasian kata yang hanya dapat mengenal kata yang diucapkan jika kata tersebut memiliki jeda waktu pengucapan antar kata.

2. Kata-kata yang berhubungan

Proses pengidentifikasian kata yang mirip dengan kata-kata terisolasi, namun membutuhkan jeda waktu pengucapan antar kata yang lebih singkat.

3. Kata-kata yang berkelanjutan

Proses pengidentifikasian kata yang sudah lebih maju karena dapat mengenal kata-kata yang diucapkan secara berkesinambungan dengan jeda waktu yang sangat sedikit atau tanpa jeda waktu. Proses pengenalan suara ini sangat rumit karena membutuhkan metode khusus untuk membedakan katakata yang diucapkan tanpa jeda waktu. 
Pengguna perangkat ini dapat mengucapkan kata-kata secara natural.

4. Kata-kata spontan

Proses pengidentifikasian kata yang dapat mengenal kata-kata yang diucapkan secara spontan tanpa jeda waktu antar kata.

5. Verifikasi atau identifikasi suara

Proses pengidentifikasian kata yang tidak hanya mampu mengenal kata, namun juga mengidentifikasi siapa yang berbicara [3].

\section{FFT}

FFT (Fast Fourier Transform) adalah teknik perhitungan cepat dari DFT. DFT digunakan untuk melakukan analisa frekuensi dari sinyal waktu diskrit

$\mathrm{X}(\mathrm{n}) \mathrm{N}$ peint DFT $\rightarrow \mathrm{X}(\mathrm{k})$ dimana $\mathrm{n}=0, \ldots \mathrm{N}-1$ dan $\mathrm{k}=0, \ldots . \mathrm{N}-1$

DFT dihitung menggunakan persamaan :

$$
\begin{aligned}
\mathrm{X}(\mathrm{k})= & \sum_{n=0}^{N-1} x(n) W_{N}^{k n} \operatorname{dimana} \mathrm{W}_{\mathrm{N}}=e^{-j \frac{2 p}{N}}(2.1) \\
& \text { Sehingga } \mathrm{X}(\mathrm{k})=\sum_{n=0}^{N-1} x(n) e^{j 2 p(k ? N) n}(2.2)
\end{aligned}
$$

Invers DFT (IDFT) menghitung kembali representasi sinyal waktu diskrit $\mathrm{x}(\mathrm{n})$ dari sinyal yang dinyatakan dalam domain frekuensi $X(\omega)$.

$$
\begin{aligned}
\mathrm{X}(\mathrm{k}) & =\frac{1}{N} \sum_{n=0}^{N-1} x(n) e^{j 2 p(k ? N) n} \\
& =\frac{1}{N} \sum_{n=0}^{N-1} x(k) W_{N}^{k n}
\end{aligned}
$$

Dimana $\mathrm{W}_{\mathrm{N}}=e^{-j \frac{2 p}{N}} \rightarrow$ akar ke $\mathrm{N}$ dari unity

Fast Fourier Transform adalah suatu algoritma yang digunakan untuk mempresentasikan sinyal dalam domain waktu diskrit menjadi domain frekuensi.Fast Fourier Transform (FFT) ditemukan tahun 1965 merupakan pengembangan dari Fourier Transform (FT).penemu FT adalah J.Fourier pada tahun 1822. FT membagi sebuah sinyal menjadi frekuensi yang berbeda-beda dalam fungsi ekponensial yang kompleks
Definisi Fast Fourier Transform (FFT) adalah metode yang sangat efisien untuk menghitung koefisien dari Fourier diskrit ke suatu finite sekuen dari data yang komplek. Transformasi Fourier didefinisakan oleh rumus :

$$
F(k)=\sum_{n=1}^{N} f(n) e^{-\frac{j 2 p n k}{N}}(2.5)
$$

Dimana $f(k)$ adalah snyal dalam domain frekuensi (Frekuensi domain), $f(n)$ adalah sinyal dalam domain waktu (time domain), dan $e^{-\frac{j 2 p n k T}{N}}$ adalah konstanta dari nilai sebuah sinyal, $\mathrm{k}$ adalah frekuensi dan $\mathrm{t}$ adalah waktu.

Atau dapat ditulis dengan

$$
\begin{aligned}
& f(k)=\sum_{n=1}^{N} f(n) \cos (2 p n k T / N)-(2.6) \\
& j \sum_{n=1}^{N} f(n) \sin (2 p n k T / N)
\end{aligned}
$$

Untuk melihat nilai hasil FFT digunakan rumus :

$|f(u)|=\left[R^{2}+I^{2}\right]^{1 / 2}(2.8)$

Fast Fourier Transform (FFT) merupakan salah satu metode untuk transformasi sinyal suara dalam domain waktu menjadi sinyal dalam domain frekuensi, artinya proses perekaman suara disimpan dalam bentuk digital berupa gelombang Spectrum suara yang berbasis frekuensi sehingga lebih mudah dalam menganalisa spectrum frekuensi suara yang telah direkam.[4]

\section{Euclidean Distance (Jarak Euclidean)}

Euclidean distance adalah metode klasifikasi tetangga terdekatnya dengan menentukan jarak antara dua buah objek, perbandingan ini dapat dilakukan dengan cara menghitung jarak Euclidean (Euclidean Distance), yang merupakan selisih antara 2 buah vector yang akan dibandingkan untuk pengenalan sebuah objek yang akan diuji. Metode Euclidean sangan baik untuk pengenalan. Rumus perhitungan jarak ditulis sebagai berikut[5]

$$
d_{e}=\sqrt{\sum_{j=1}^{m}\left(F d_{i, k}-k_{j}\right)^{2}}
$$

Keterangan:

$d_{e}=$ jarak Euclidean 
$F d_{i}=$ matrik fitur yang dihasilkan oleh data pelatihan ke i

$k_{j}=$ data bobot dengan test

$m$ = jumlah data pelatihan

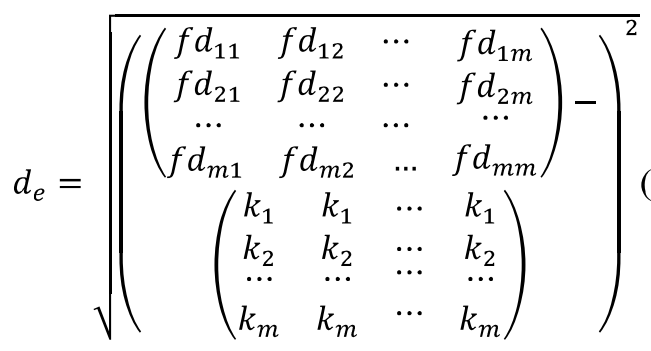

$d_{i}$

$\left.=\mid \sqrt{\left(f d_{1 i}-k_{1}\right) 2+\left(f d_{2 i}-k_{2}\right)+\cdots+\left(f d_{m i}-k_{m}\right)} 2\right]$ (2.13)

Dimana:

$i \quad=1,2,3, \ldots, \mathrm{M}$

$d_{e i}=\left[d_{1}, d_{2}, \ldots, \mathrm{c}\right]$

Dari bobot Euclidean $\left(d_{e}\right)$ diaatas yang mempunyai bobot paling kecil akan digunakan sebagai nilai fitness yang untuk pengenalan.

\section{BAHAN DAN METODE}

Selanjutnya Metode penelitian meliputi perancangan sistem perangkat keras dan perangkat lunak. Informasi data meliputi mic sebagai input data klasifikasi kemudian diproses dalam aplikasi rad studio xe7 dan mengirim perintah ke miktrokontroller ATMega 16

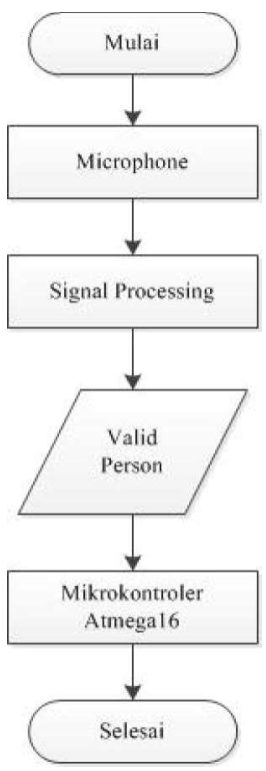

Gambar 2 Perancangan sistem

Penjelasan dari flowchart sistem dari identifikasi suara diatas adalah sebagai berikut:

Dari gambar flowchart sistem diatas bias diketahui bahwa cara kerja sistem dimulai dengan perekaman suara melalui microphone yang terhubung dengan port atau jack pada laptop atau komputer, kemudian dilakukan pemrosesan sinyal menggunakan FFT (Fast Fourier Transform) dan VAD (Voice Activity Detection). Dan selanjutnya mencocokkan valid person atau orang yang memiliki hak akses digunakan jarak euclidean untuk mengetahui hasil sesuia atau tidak dengan data yang telah ditentukan sebelumnya. Jika output sesuai maka sistem akan mengirimkan karakter perintah melalui komunikasi USART AVR

\section{HASIL DAN PEMBAHASAN}

Dalam pengujian sistem identifikasi suara terdapat beberapa tahapan, mulai dari pengujian dengan menggunkan nama masing-masing, suara pria dan wanita juga pengujian menggunakan media player.

\section{PengujanPengujian Sistem Identifikasi Menggunakan 1 Kata Yang Sama}

Dalam pengujain ini kata kunci yang dijadikan patokan untuk 10 data sebagai orang yang memili hak akes menggunakan 1 kata yang sama yaitu kata "BUKA". Dengan ketentuan 1 sampel memiliki 10 kali kesempatan untuk melakukan percobaan. Selain itu pada percobaan ini menggunakan 2 kondisi, dimana kondisi 1 adalah 1 data partisipan dibandingkan dengan partisipan yang bersangkutan, sedangkan kondisi 2 adalah semua data partisipan dibandingkan dengan salah satu partisipan.

Berikut adalah table hasil percobaan sistem identifikasi dengan 1 kata yang sama:

Tabel 1. Hasil pengujian menggunakan 1 kata

\begin{tabular}{|c|c|c|}
\hline $\begin{array}{c}\text { Nama } \\
\text { Parisipan }\end{array}$ & $\begin{array}{c}\text { Jumlah } \\
\text { keberhasilan }\end{array}$ & $\begin{array}{c}\text { Jumlah } \\
\text { kegagalan }\end{array}$ \\
\hline Iqbal & 7 & 3 \\
\hline Daus & 7 & 3 \\
\hline Fajar & 8 & 2 \\
\hline Candra & 2 & 8 \\
\hline Iyan & 6 & 4 \\
\hline Dedy & 6 & 4 \\
\hline Ilyas & 7 & 3 \\
\hline Ivan & 6 & 4 \\
\hline Wacket & 7 & 3 \\
\hline Septian & 5 & 5 \\
\hline Pada tabel 1 menunjukkan hasil dari
\end{tabular}

pengujian menggunakan 1 kata yang sama 
kondisi 1. Nilai eror dari pengujian dengan menggunakan 1 kata yang sama dapat dihitung dengan menggunakan rumus berikut:

\section{Presentase Kegagalan}

$=\frac{\text { Jumlah kegagalan }}{\text { Jumlah Data Keseluruhan }} \times 100 \%$

Sehingga, didapatkan nilai kegagalan untuk pengujian dengan menggunakan 1 kata yang sama kondisi 1 sebagai berikut:

Tabel 2 Presentase kegagalan pengujian menggunakan 1 kata kondisi 1

\begin{tabular}{|c|c|}
\hline $\begin{array}{c}\text { Nama } \\
\text { Parisipan }\end{array}$ & $\begin{array}{c}\text { Presentasan } \\
\text { Kegagalan }\end{array}$ \\
\hline Iqbal & $30 \%$ \\
\hline Daus & $30 \%$ \\
\hline Fajar & $20 \%$ \\
\hline Candra & $80 \%$ \\
\hline Iyan & $40 \%$ \\
\hline Dedy & $40 \%$ \\
\hline Ilyas & $30 \%$ \\
\hline Ivan & $40 \%$ \\
\hline Wacket & $30 \%$ \\
\hline Septian & $50 \%$ \\
\hline
\end{tabular}

Tabel 3. Hasil pengujian menggunakan 1 kata yang sama kondisi 2

\begin{tabular}{|c|c|c|c|c|}
\hline \multirow[t]{2}{*}{$\begin{array}{c}\text { Nama } \\
\text { Parisip } \\
\text { an }\end{array}$} & \multirow[t]{2}{*}{$\begin{array}{c}\text { Jumlah } \\
\text { keberhasi } \\
\text { lan }\end{array}$} & \multirow[t]{2}{*}{$\begin{array}{c}\text { Jumlah } \\
\text { kegagal } \\
\text { an }\end{array}$} & \multicolumn{2}{|c|}{$\begin{array}{c}\text { Kesesuaian } \\
\text { data dari } \\
\text { keberhasila } \\
\text { n }\end{array}$} \\
\hline & & & $\begin{array}{l}\text { Sesu } \\
\text { ai }\end{array}$ & $\begin{array}{l}\text { Tida } \\
\mathrm{k}\end{array}$ \\
\hline Iqbal & 6 & 4 & 4 & 2 \\
\hline Daus & 5 & 5 & 3 & 2 \\
\hline Fajar & 7 & 3 & 5 & 2 \\
\hline Candra & 7 & 3 & 4 & 3 \\
\hline Iyan & 6 & 4 & 3 & 3 \\
\hline Dedy & 7 & 3 & 5 & 2 \\
\hline
\end{tabular}

\begin{tabular}{|c|c|c|c|c|}
\hline Ilyas & 5 & 5 & 3 & 2 \\
\hline Ivan & 6 & 4 & 5 & 1 \\
\hline Wacket & 7 & 3 & 2 & 5 \\
\hline Septian & 7 & 3 & 5 & 2 \\
\hline
\end{tabular}

Pada tabel 3 menunjukkan hasil dari pengujian menggunakan 1 kata yang sama kondisi 2, dimana kondisi 2 menggunakan semua data partisipan yang telah disimpan sebelumnya. Nilai presentase kegagalan dapat dihitung menggunakan rumus sebagai berikut:

$$
\begin{aligned}
& \text { Presentase Kegagalan } \\
& =\frac{\text { Jumlah kegagalan }}{\text { Jumlah Data Keseluruhan }} \times 100 \%
\end{aligned}
$$

Sedangkan nilai tingkat kesesuaian data dapat dihitung dengan menggunakan rumus sebagai berikut:

$$
\begin{aligned}
& \text { Tingkat kesesuaian } \\
& =\frac{\text { Jumlah Sesuai }}{\text { Jumlah keberhasilan }} \times 100 \%
\end{aligned}
$$

Sehingga, didapatkan nilai kegagalan dan tingkat kesesuaian untuk pengujian dengan menggunakan 1 kata yang sama kondisi 2 sebagai berikut:

Tabel 4 Presentase kegagalan dan tingkat kesesuaian

\begin{tabular}{|c|c|c|}
\hline $\begin{array}{l}\text { Nama } \\
\text { Parisipan }\end{array}$ & $\begin{array}{l}\text { Presentase } \\
\text { kegagalan }\end{array}$ & $\begin{array}{l}\text { Tingkat } \\
\text { kesesuaian }\end{array}$ \\
\hline Iqbal & $40 \%$ & $40 \%$ \\
\hline Daus & $50 \%$ & $30 \%$ \\
\hline Fajar & $30 \%$ & $50 \%$ \\
\hline Candra & $30 \%$ & $40 \%$ \\
\hline Iyan & $40 \%$ & $30 \%$ \\
\hline Dedy & $30 \%$ & $50 \%$ \\
\hline Ilyas & $50 \%$ & $30 \%$ \\
\hline Ivan & $40 \%$ & $50 \%$ \\
\hline
\end{tabular}




\begin{tabular}{|c|c|c|}
\hline Wacket & $30 \%$ & $20 \%$ \\
\hline Septian & $30 \%$ & $50 \%$ \\
\hline
\end{tabular}

\section{Pengujian Dengan Menggunakan Nama Partisipan}

Pada pengujian ini partisipan diminta untuk menyebutkan nama masing-masing kemudian disimpan sebagai data acuan untuk dibandingkan dengan data yang akan direkam ulang secara langsung. Pada pengujian ini kesempatan yang diberikan bagi partisipan untuk melakukan percobaan sama dengan pada pengujian sebelumnya

Table 5 Pengujian menggunakan nama

partisipan

\begin{tabular}{|c|c|c|}
\hline $\begin{array}{c}\text { Nama } \\
\text { Parisipan }\end{array}$ & $\begin{array}{c}\text { Jumlah } \\
\text { keberhasilan }\end{array}$ & $\begin{array}{c}\text { Jumlah } \\
\text { kegagalan }\end{array}$ \\
\hline Iqbal & $70 \%$ & $30 \%$ \\
\hline Daus & $70 \%$ & $30 \%$ \\
\hline Fajar & $60 \%$ & $40 \%$ \\
\hline Candra & $20 \%$ & $80 \%$ \\
\hline Iyan & $70 \%$ & $30 \%$ \\
\hline Dedy & $40 \%$ & $60 \%$ \\
\hline Ilyas & $60 \%$ & $40 \%$ \\
\hline Ivan & $60 \%$ & $40 \%$ \\
\hline Wacket & $70 \%$ & $30 \%$ \\
\hline Septian & $50 \%$ & $50 \%$ \\
\hline
\end{tabular}

Tabel 5 menunjukkan hasil dari

pengujian menggunakan nama partisipan.

Presentase kegagalan pada percobaan yang telah dilakukan dapat dihitung menggunakan rumus berikut

\section{Presentase Kegagalan}

$=\frac{\text { Jumlah kegagalan }}{\text { Jumlah Data Keseluruhan }} \times 100 \%$

Sehingga, didapatkan nilai presentase kegagalan pada percobaan sebagai berikut:

Tabel 6 Presentasi kegagalan pengujian menggunakan nama partisipan

\begin{tabular}{|c|c|}
\hline Nama Parisipan & $\begin{array}{c}\text { Presentasan } \\
\text { Kegagalan }\end{array}$ \\
\hline Iqbal & $30 \%$ \\
\hline Daus & $30 \%$ \\
\hline Fajar & $40 \%$ \\
\hline Candra & $80 \%$ \\
\hline Iyan & $30 \%$ \\
\hline Dedy & $60 \%$ \\
\hline Ilyas & $40 \%$ \\
\hline Ivan & $40 \%$ \\
\hline Wacket & $30 \%$ \\
\hline Septian & $50 \%$ \\
\hline
\end{tabular}

\section{Pengujian Menggunakan Media Player}

Pada pengujian ini file suara dari partisipan yang telah disimpan sebelumnya dibandingkan dengan suara yang direkam menggunakan ponsel genggam, dalam kondisi ini sistem diuji coba untuk bisa mengenali apakah itu suara yang berasal langsung dari para partisipan atau dari media player untuk mengetahui responsifitas sistem. Pada percobaan ini kesempatan yang diberikan untuk partisipan adalah 5 kali percobaan.

Table 7. Hasil pengujian menggunakan media player

\begin{tabular}{|c|c|c|}
\hline $\begin{array}{c}\text { Nama } \\
\text { Parisipan }\end{array}$ & $\begin{array}{c}\text { Jumlah } \\
\text { keberhasilan }\end{array}$ & $\begin{array}{c}\text { Jumlah } \\
\text { kegagalan }\end{array}$ \\
\hline Yoko & 0 & 5 \\
\hline Arina & 1 & 4 \\
\hline Laily & 1 & 4 \\
\hline Yuni & 1 & 4 \\
\hline Azemi & 2 & 3 \\
\hline Iqbal & 1 & 4 \\
\hline Umar & 0 & 5 \\
\hline Pungki & 1 & 4 \\
\hline Sita & 0 & 5 \\
\hline
\end{tabular}


Tabel 7 diatas menunjukkan hasil dari pengujian menggunakan media player dimana presentase kegagalan dari percobaan yang telah dilakukan dapat dihitung menggunakan rumus sebagai berikut:

$$
\begin{aligned}
& \text { Presentase Kegagalan } \\
& =\frac{\text { Jumlah kegagalan }}{\text { Jumlah Data Keseluruhan }} \times 100 \% \\
& \text { Sehingga, setelah dilakukan } \\
& \text { perhitungan didapatkan presentase } \\
& \text { kegagalan pada percobaan ini sebagai }
\end{aligned}
$$

Tabel 8 Presentase kegagalan pengujian dengan media player

\begin{tabular}{|c|c|}
\hline $\begin{array}{c}\text { Nama } \\
\text { Parisipan }\end{array}$ & $\begin{array}{c}\text { Presentasan } \\
\text { Kegagalan }\end{array}$ \\
\hline Yoko & $100 \%$ \\
\hline Arina & $80 \%$ \\
\hline Laily & $80 \%$ \\
\hline Yuni & $80 \%$ \\
\hline Azemi & $60 \%$ \\
\hline Iqbal & $80 \%$ \\
\hline Umar & $100 \%$ \\
\hline Pungki & $80 \%$ \\
\hline Sita & $100 \%$ \\
\hline
\end{tabular}

\section{KESIMPULAN}

Kesimpulan yang didapat berdasarkan perancangan, implementasi, dan pengujian hasil prototype dan system yang telah dibuat dapat disimpulkan bahwa:

1. Setelah dilakukan pengujian dapat disimpulkan bahwa eror dipengaruhi oleh pengucapan yang kurang pas dengan data sebelumnya yang telah direkam.

2. Kelemahan pada system ini adalah ketika warna suara data yang disimpan sebagai acuan dengan data yang diuji memiliki kemiripan, serta jika ketepatan start dan stop oleh partisipan yang belum pernah direkam sebelumnya memiliki kemiripan maka akan terjadi eror.

\section{DAFTAR PUSTAKA}

[1] Angga Setiawan, Achmad Hidayatno, R. Rizal Isnanto. "Aplikasi Pengenalan Ucapan dengan Ekstraksi Mel-Frequency Cepstrum Coefficients (MFCC) Melalui Jaringan Syaraf Tiruan (JST) Learning Vector Quantization (LVQ) untuk Mengoperasikan Kursor Komputer". TRANSMISI, ISSN 1411-0814. 2011.

[2] Steven W. Smith. "The Scientist and Engineer's Guide to Digital Signal Processing: Second Edition". San Diego: California Technical Publishing, 1999.

[3] Agung Andika Putra. "TEKNOLOGI PENGENALAN SUARA (VOICE RECOGNITION)".

http://indonesianecho.blogspot.co.id/2015/1 1/voice-recognition-a.html. Halaman ini terakhir diubah pada rabu, 11 November 2015. Diakses 16 Mei 2017

[4] Sipasulta,Reonaldo Yohanes.dkk. "Simulasi Sistem Pengacak Sinyal Dengan Metode FFT(Fast Fourier Transform)". E-journal Teknik Elektro dan Komputer (2014),ISSN 2301-8402

[5] Emma Utamidan Resty Wulaningrum. 2014. "Penggunaan Principal Component Analiysis dan Euclidean Distance Untuk Identifikasi Citra Tanda Tangan”. Kediri: Jurnal Ilmu Pengetahuan Teknilogi Dan Komputer (IPTEK-KOM). Vol. 16 No. 1. 